\title{
Impact of Coping on Mental Health of Convicted Prisoners
}

\author{
Savita Chahal ${ }^{1}$, Sumit Rana ${ }^{2} *$, Priti Singh ${ }^{3}$
}

\section{ABSTRACT}

Background and Objectives: The coping strategies account for significant variance in psychological distress and psychiatric morbidity among different prisoners despite being in the same environment. Since the coping strategies and the resources available to each person differ, sometimes dramatically, the effect of incarceration will therefore vary and there is no simple formula to predict outcomes. The aim of the present study was to explore the differences in coping strategies of convicts with and without psychiatric morbidity. Method: All the convicts (200) were divided into two groups i.e. those with and without psychiatric morbidity after initial screening for psychological distress by GHQ 12 followed by diagnostic evaluation using MINI and were subsequently compared regarding the differences in the coping strategies adopted by them using Coping Strategies Checklist. Results: Prisoners without psychiatric morbidity predominantly used denial $(7.46 \pm 2.12)$ and externalization $(3.63 \pm 1.24)$ as the coping strategies as compared to prisoners with psychiatric illness. Convicts with psychiatric disorders had used a significantly higher number of coping strategies (18.95 \pm 3.91$)$ compared to those without psychiatric morbidity (16.37 \pm 3.21$)$ and had mainly relied upon internalization (7.21 \pm 2.42$)$ and anger $(0.50 \pm .82)$ as the coping mechanisms. Male convicts were more likely to use anger to cope with the prison stress. Conclusion: The use of maladaptive and ineffective coping mechanisms such as internalization and anger was more common among convicts with psychiatric morbidity. Specific psychological interventions in enhancing constructive coping strategies employed by the prisoners are of utmost importance as this will enable them to better cope up with the trauma of conviction and will help in reducing the mental health problems.

Keywords: Coping strategies, convicts, psychiatric morbidity

Crime is a universal phenomenon that appeared in all ages and it is prevalent till now. As the country is growing economically, crime rate is also moving rapidly. As per the ninth edition of the World Prison Population List, the prison population of India is 332,112. ${ }^{1}$ around the world; prison “appears to be good incubator for developing mental health problems." There are two categories of mentally ill patients within the prison walls. First, the individuals who were

\footnotetext{
${ }^{1}$ Senior Resident, Department of Psychiatry, Pt. B. D Sharma, PGIMS Rohtak

${ }^{2}$ Assistant Professor, Department of Psychiatry, Pt. B. D Sharma, PGIMS Rohtak

${ }^{3}$ Professor, Department of Psychiatry, Pt. B. D Sharma, PGIMS Rohtak

*Responding Author

(C) 2016 I S Chahal, S Rana, P Singh; licensee IJIP. This is an Open Access Research distributed under the terms of the Creative Commons Attribution License (http://creativecommons.org/licenses/by/2.0), which permits unrestricted use, distribution, and reproduction in any Medium, provided the original work is properly cited.
} 
mentally ill, even before coming to the prison. Second category is of the people who become psychiatrically deranged after incarceration. ${ }^{2,3}$

"Emotional and psychological survival of a prisoner partly depends upon an individual's ability to tolerate the deprivations of prison which in turn is determined by the individual coping skills, personality factors, level of social support and resources available to them. The Coping styles thus account for significant variance in psychological distress and psychiatric morbidity among different prisoners despite being in the same environment. ${ }^{4}$ Coping may be defined as "constantly changing cognitive and behavioral efforts to manage specific external and/or internal demands that are appraised as taxing or exceeding the resources of the person". One may use emotion-focused coping that involves handling the emotional response to the situation with feelings such as guilt or anger or the problem focused coping in which efforts are directed at defining the problem, generating alternative solutions, weighing the alternatives in terms of their costs and benefits, choosing among them, and acting. ${ }^{5}$

The coping skills are particularly important for inmates who must learn to adapt to an entirely new stressful environment which is fundamentally different from life outside the gates. However, many inmates come into the correctional system with personal constraints such as abuse, poverty and little education along with the environmental constraint of being imprisoned. These constraints make it difficult to cope and adjust to the prison environment. ${ }^{5}$ Coping Strategies typically identified among criminal populations include avoidance, momentary relief of problems with little thought to consequences, and aggressive behaviour. As unhealthy coping is continued, problems again worsen, and the pattern continues. ${ }^{6} \mathrm{~A}$ problem focused coping style is likely to be less effective for inmates because- with the exception of escape- there are not many behavioural coping strategies available, and one cannot undo the crime. Therefore emotion focused coping may be more effective under these circumstances. ${ }^{7}$

The coping strategies and the resources available to each person differ, sometimes dramatically. The effect of incarceration will therefore vary and there is no simple formula to predict outcomes. ${ }^{8}$ Since there are only limited publications pertaining to theoretical and/or empirical issues of coping for mentally disordered offenders and the profound scarcity of Indian literature on coping skills and its relation with the mental health of prisoners prompted the current study with the following aims:

1. To study the socio-demographic, criminological and psychiatric variables of the convicts.

2. To analyze the gender differences in coping strategies employed by convicts.

3. To compare the coping strategies of Convicts with and without psychiatric morbidity.

\section{METHOD}

This was a cross sectional study conducted in the district jail, Rohtak, Haryana in India from October 2011 to December 2012. All the convicted prisoners of District Jail constituted the study sample after being screened for the following criteria. 


\section{Impact of Coping on Mental Health of Convicted Prisoners}

\section{Inclusion criteria}

1. Convicted prisoners of either sex aged $\geq 18$ years

2. Giving written informed consent

\section{Exclusion criteria}

1. Organic brain syndromes

2. Subjects with chronic severe physical illnesses

3. Prisoners temporarily shifted from other jails of the state on medical grounds

\section{Tools}

The following tools were used:

1) A specially designed proforma for socio-demographic, criminological variables and psychiatric history of convicts

2) General Health Questionnaire-12 (Hindi Version) GHQ-12 : used in the present study is based on the Hindi translation of the 60-item General Health Questionnaire that has been standardized in India and in Indian population ${ }^{9,10}$ and valid and reliable self administered screening measure for psychological problems. In the present study, to define a case with possible psychiatric morbidity a score of 2 was used. The GHQ-12 has a sensitivity of $89 \%$ and specificity of $80 \%$.

3) Mini International Neuropsychiatric Interview (MINI): It is a short, structured diagnostic interview developed by an international group of psychiatrists and clinicians used to diagnose DSM-IV and ICD 10 psychiatric disorders. ${ }^{11}$ The MINI has been demonstrated to have good to very good validity, reliability (inter rater and test-retest), sensitivity and specificity indices. ${ }^{12,13}$ It has relatively brief administration time (15-20 min) and ease of use. The MINI has also been used in prisons. ${ }^{14,15}$

4) Coping Strategy Checklist (CSCL) -Hindi: Coping Strategies Check List-Hindi (CSCL) 16: It is a self-administered yes/no checklist with high reliability. It lists coping strategies used by people to deal with the situations which trouble them. The checklist covers all stressors and is not disease-specific. The 36 strategies have been factored into five factors: denial, internalize, externalize, emotional outlet, and anger. A higher score indicates greater use of coping strategies. It was translated into Hindi with Cronbach's alpha of 0.64 in PGIMER Chandigarh. The scale has good face validity, inter-rater reliability, internal consistency and agreement between English and Hindi versions. ${ }^{17}$

\section{Procedure}

Prior written permission from the Director General of Prisons, Haryana was sought regarding the study. An alphabetically arranged list of all the convicted prisoners was obtained from the Jail Superintendent's office following which all convicted prisoners of the District jail, Rohtak were included on the basis of assessment as per the inclusion and exclusion criteria. The entire interview took place in a separate room of the prison hospital with proper security but intact privacy where the prisoners were brought by the prison warders. A special proforma designed for socio-demographic, criminological variables and psychiatric history was filled for all the 
convicts. The subjects were screened for psychological distress using General health questionnaire (GHQ12) -Hindi version .Those that were screened GHQ positive were further subjected to diagnostic evaluation for psychiatric morbidity using Mini International Neuropsychiatric Interview (MINI). Coping strategies in all convicted prisoners were assessed using Coping Strategy Check List (CSCL) -Hindi. If any subject could not read, assisted application was used, in which the researcher read the instruments and marked the correct responses.

Ethical approval was sought from the Institutional Ethics Committee.

\section{Statistical Analysis}

The data was analyzed using SPSS Version 10.0. For Descriptive statistics frequencies, percentages, means and standard deviations of different variables were calculated. Non Parametric tests were used as the data did not follow normal distribution on KolmogorovSmirnov test of normality. Kruskal-Wallis one-way analysis of variance by ranks was used for comparing more than two samples and Mann Whitney Test was used for comparing two samples. The probability level of significant difference was set at $<0.05$.

\section{RESULTS}

This was a cross sectional study carried out in district jail Rohtak. The jail houses around 1200 prisoners at any time which is around four times its sanctioned capacity of 350 prisoners. Most of them are males. A large number of prisoners (up to 80\%) are under trials and their criminal cases are still in different stages of the legal process. About 20\% (257) of prisoners are convicts and are serving their sentence.

During the study period, 32 convicts were shifted to District Jail Jhajjar following its construction. Previously District Jail Rohtak used to serve as common prison for both districts Rohtak and Jhajjar. 2 convicts had completed their sentence and were released.1 refused consent to participate in the study. 2 prisoners could not understand the nature of questions asked due to intellectual compromise and were therefore excluded. 20 convicts were suffering from severe chronic physical illnesses like AIDS (2), Cancer (2), chronic kidney disease (1), cardiovascular disease (2), chronic respiratory illness (2), Tuberculosis with complications (3), debilitating Rheumatoid arthritis (1), Epilepsy (3), Diabetes Mellitus (2), CVA (1), Blindness (1). Excluding these 57 convicts, a total of 200 convicts constituted the final study sample.

As depicted in table 1, Out of a total of 200 prisoners, 77.5\% were males. Majority (61\%) of the prisoners were in the age group of 22- 39 years. Only a minority (2.5\%) were below 21 years. Almost one third had studied till primary level with matriculates being the second highest group with $22.5 \%$. Slightly more than half were employed. Most (79\%) of our subjects hailed from rural areas and nearly half (49\%) of them belonged to nuclear families. Slightly more than half (53\%) were married. Fourteen (7\%) convicts had a self reported past history of psychiatric 
illness with 3(1.5\%) receiving in-patient psychiatric treatment and 10 (5\%) received only outpatient treatment. $9(4.5 \%)$ had a family history of psychiatric illness in first degree relatives.

Table 1: Socio-Demographic Characteristics and Psychiatric History of Convicts

\begin{tabular}{|c|c|c|c|}
\hline VARIABLE & & $\begin{array}{l}\text { FREQUENCY } \\
\text { (n) }\end{array}$ & $\begin{array}{l}\text { PERCENTAGE } \\
(\%)\end{array}$ \\
\hline \multirow{2}{*}{ Gender } & Male & 155 & 77.5 \\
\hline & Female & 45 & 22.5 \\
\hline \multirow{5}{*}{$\begin{array}{l}\text { Age Distribution } \\
\text { (In Years) }\end{array}$} & $18-21$ & 05 & 2.5 \\
\hline & $22-29$ & 60 & 30.0 \\
\hline & $30-39$ & 62 & 31.0 \\
\hline & $40-49$ & 32 & 16.0 \\
\hline & Above 50 & 41 & 20.5 \\
\hline \multirow{6}{*}{$\begin{array}{l}\text { Educational } \\
\text { Status }\end{array}$} & Illiterate & 43 & 21.5 \\
\hline & Primary & 61 & 30.5 \\
\hline & Matriculation & 45 & 22.5 \\
\hline & Higher Secondary & 34 & 17.0 \\
\hline & Graduation & 15 & 7.5 \\
\hline & Post Graduation & 02 & 1.0 \\
\hline \multirow{2}{*}{$\begin{array}{l}\text { Prior } \quad \text { Employment } \\
\text { Status }\end{array}$} & Employed & 108 & 54.0 \\
\hline & Unemployed & 92 & 46.0 \\
\hline \multirow{5}{*}{ Marital Status } & Single & 58 & 29.0 \\
\hline & Married & 106 & 53.0 \\
\hline & Separated & 07 & 3.5 \\
\hline & Divorced & 06 & 3.0 \\
\hline & Widow/widower & 23 & 11.5 \\
\hline \multirow{2}{*}{ Background } & Rural & 158 & 79.0 \\
\hline & Urban & 42 & 21.0 \\
\hline \multirow{3}{*}{ Family Structure } & Nuclear & 98 & 49.0 \\
\hline & Joint & 77 & 38.5 \\
\hline & Extended & 25 & 12.5 \\
\hline \multirow{3}{*}{ Past Psychiatric History } & $\begin{array}{l}\text { Previous In }- \text { Patient } \\
\text { Treatment }\end{array}$ & 03 & 1.5 \\
\hline & $\begin{array}{lll}\text { Previous } & \text { Out } & \text {-Patient } \\
\text { Treatment } & & \\
\end{array}$ & 10 & 5.0 \\
\hline & $\begin{array}{l}\text { Untreated psychiatric } \\
\text { illness }\end{array}$ & 01 & 0.5 \\
\hline $\begin{array}{l}\text { Family History of } \\
\text { Psychiatric Illness }\end{array}$ & Positive & 09 & 4.5 \\
\hline
\end{tabular}

The most common offence associated with conviction was murder (52.5\%) followed by dowry related crime (9.0\%), drugs related offences (6.5\%), dacoity (6.5\%), rape and sexual offences (3.5\%) and others related to property disputes, forgery, financial offences, thefts, flesh trade etc 
in that order. About 101(50.1\%) were sentenced to life time imprisonment followed by imprisonment for a period of 5-10 years (17\%). Half of the prisoners had stayed in prison for a period of 1-5 years. 16 (8\%) of the prisoners had a previous prison spell for a crime other than the index offence.

Out of total 200, 163 prisoners screened positive using GHQ-12, were further subjected to diagnostic assessment for psychiatric morbidity using Mini International Neuropsychiatric Interview (MINI). One hundred nineteen convicts were found to have psychiatric illness using Mini International Neuropsychiatric Interview giving a net prevalence of psychiatric morbidity to be 59.5\%. The prevalence of individual psychiatric disorders among convicts is beyond the scope of this article.

Table 2: Gender wise Comparison of Coping Strategies of Convicts

\begin{tabular}{|c|c|c|c|c|c|}
\hline \multirow{3}{*}{ CATEGORY } & \multirow{3}{*}{ VARIABLE } & \multicolumn{2}{|l|}{ GENDER } & \multirow{3}{*}{$\mathbf{Z}$} & \multirow{3}{*}{$\mathbf{p}$} \\
\hline & & $\begin{array}{l}\text { MALE } \\
(n=145)\end{array}$ & $\begin{array}{l}\text { FEMALE } \\
(n=45)\end{array}$ & & \\
\hline & & Mean(S.D) & Mean(S.D) & & \\
\hline \multirow{6}{*}{$\begin{array}{l}\text { COPING } \\
\text { STRATEGIES }\end{array}$} & Denial & $6.99(2.20)$ & $6.51(2.55)$ & 1.19 & 0.231 \\
\hline & Internalize & $5.63(2.96)$ & $6.42(2.57)$ & 1.61 & 0.106 \\
\hline & Externalize & $3.26(1.47)$ & $3.58(0.98)$ & 1.07 & 0.281 \\
\hline & Emotional Outlet & $1.55(0.96)$ & $1.56(0.75)$ & 0.18 & 0.853 \\
\hline & Anger & $0.46(0.77)$ & $0.13(0.40)$ & 2.72 & 0.006 \\
\hline & Total & 17.91(3.88) & $18.00(3.81)$ & 0.38 & 0.698 \\
\hline
\end{tabular}

Mann Whitney $U$ test; significance level at $\mathbf{p}<0.05$

It is evident from table 2 that among the coping strategies employed, male and female convicts differed only in the use of anger as a means of coping which was statistically higher among male convicts. There was no statistically significant difference in the use of rest of coping strategies.

Table 3: Comparison of Coping Strategies of convicts with and without Psychiatric morbidity

\begin{tabular}{|c|c|c|c|c|c|}
\hline \multirow[t]{2}{*}{ CATEGORY } & \multirow[t]{2}{*}{ Variable } & $\begin{array}{l}\text { No } \\
\text { psychiatric } \\
\text { disorder } \\
(n=81)\end{array}$ & $\begin{array}{l}\text { Psychiatric } \\
\text { disorder } \\
(n=119)\end{array}$ & \multirow[t]{2}{*}{$\mathbf{Z}$} & \multirow[t]{2}{*}{$\mathbf{p}$} \\
\hline & & Mean(S.D) & Mean(S.D) & & \\
\hline \multirow{6}{*}{$\begin{array}{l}\text { COPING } \\
\text { STRATEGIES } \\
\text { (CSCL) }\end{array}$} & Denial & $7.46(2.12)$ & $6.51(2.33)$ & 3.29 & 0.001 \\
\hline & Internalize & $3.67(2.17)$ & $7.21(2.42)$ & 8.55 & $<0.001$ \\
\hline & Externalize & $3.63(1.24)$ & $3.14(1.44)$ & 2.65 & 0.008 \\
\hline & Emotional Outlet & $1.42(0.89)$ & $1.64(0.93)$ & 1.39 & 0.163 \\
\hline & Anger & $0.20(0.46)$ & $0.50(0.82)$ & 2.55 & 0.011 \\
\hline & Total & $16.37(3.21)$ & 18.95(3.91) & 4.57 & $<0.001$ \\
\hline
\end{tabular}

*Mann Whitney $\mathrm{U}$ test; significance level at $\mathbf{p}<0.05$ 
Table 3 depicts that psychiatrically healthy prisoners used denial (7.46, S.D=2.12) and externalization (3.63, S.D=1.24) as the coping strategies as compared to prisoners with psychiatric illness. The difference was statistically significant. Convicts with psychiatric illnesses scored significantly higher on internalization (7.21, S.D=2.42) and anger (0.50, S.D=0.82) as the coping mechanisms. Those with psychiatric disorder had used a significantly higher number of coping strategies (18.95, S.D =3.91) compared to those without psychiatric illness (16.37, S.D=3.21).

\section{DISCUSSION}

All the international and national researches consistently show that prisons hold a high proportion of prisoners with mental disorders. But only a handful of studies have attempted to delineate the possible factors responsible for generation of psychopathology in some and not all prisoners despite being in the same prison environment. Inmates react differently to the pressures of the prison environment and some may adapt successfully to such an environment while others may not. Since individual coping strategies could significantly affect the mental health of prisoners and keeping in view the dearth of such literature, we planned to carry out the current study with the aim to compare the diverse coping strategies adopted by convicts with and without psychiatric disorder.

For the purpose of the study we selected only the convicts as the mixing of under trial and convicted prisoners do not yield an accurate account owing to differences in the prevalence of psychiatric morbidity and differences in the mindset regarding uncertainty of the outcome and prolonged legal proceedings involved. All the convicts were selected from a single jail so as to eliminate the confounders related to prison environment, resources and support available inside the jail.

In our study, we found that male prisoners more frequently used anger as coping mechanism to overcome the stress of imprisonment compared to female prisoners. It is clear that there are gender differences in the ways that men and women cope. Women differ from men in the way that they react to a situation because of the differences in their development, upbringing and socialization.

This finding has also been supported by Clements ${ }^{18}$ who mentioned in his review article that when privacy and adequate personal space are denied to inmates, they become particularly stressed. This stress creates an increase in aggression, both physically and verbally, as a way of coping. This style of coping is then adopted in order to emphasize their dominance to other inmates more particularly in males. The lack of activities for inmates to participate in creates idleness and boredom which can result in aggression.

Previous Studies also show that the way in which men and women cope while imprisoned differs in that women tend to form family structures in an effort to recreate the roles they would normally follow in society; however, men tend to isolate themselves from others and tend to be 
more aggressive towards the other inmates. ${ }^{19,}{ }^{20}$ There was no significant difference between male and female prisoners relating to the use of other coping mechanisms.

The two groups of convicts in the study; those with and without psychiatric disorders, differed significantly on the total coping score. The group of psychiatrically ill convicts scored significantly higher on total coping score but internalization and anger were the most commonly employed coping mechanisms. This indicates that even though prisoners with psychiatric morbidity used higher number of coping strategies to adapt to the stressful situation but the strategies used were either ineffective or maladaptive.

Internalization as a coping mechanism is understood as a maladaptive coping in which a person blames self for all the wrong things, which can lead to psychopathology. This is particularly important because negative emotions such as disappointment and regret are related to psychological and physical health. Suppressing these negative emotions can also have adverse consequences. Similarly anger is also considered to be an inefficient strategy which may increase the risk of the distress.

On the contrary, denial and externalization were most commonly used coping strategies among healthy prisoners. Denial involves either complete ignoring of the stressful situation or minimization of its seriousness. It is useful in allaying anxiety arising out of different fears related to imprisonment at least during the initial periods following incarceration. Denial may not eliminate negative mood states but may help prisoners distance themselves from negative thoughts and feelings, thereby fostering feelings of hope for a positive health outcome. Denial in the form of avoiding all thoughts about the possible devastating effects of incarceration may particularly benefit some prisoners at least.

Externalizing prisoners are more socially active, blame other people or external objects for their behavior or problems, ventilate their emotions, and seek help and sympathy from others leading to at least some sense of relief from the stressful situation.

As there are no western studies that have used coping strategies check list to assess coping strategies among prisoners, and furthermore we could not find any Indian study examining the coping strategies among prisoners despite best of our efforts so we were not able to compare our findings with the existing literature.

\section{CONCLUSION}

Psychiatric morbidity was present in 59.5\% of the convicts. The convicts with psychiatric disorder had used significantly higher number of coping strategies compared to those without psychiatric disorder but they had mostly employed maladaptive and ineffective coping mechanisms such as internalization and anger. On the other hand psychiatrically healthy prisoners had predominantly relied upon denial and externalization as the coping strategies. 
Specific psychological interventions, especially in enhancing constructive coping strategies employed by the prisoners are of utmost importance in this population. This will enable them to better cope up with the trauma of conviction and will help in reducing the mental health problems and also improve subjective feeling of well-being. Since internalization as a coping strategy was most significantly associated with the development of psychiatric disorders. This suggests that some sort of program or group work which encourages inmates to share their feelings, rather than suppressing them, could be beneficial. Male prisoners should be particularly targeted for anger management training.

\section{LIMITATIONS}

- $\quad$ The participants were recruited from a single prison of the country.

- $\quad$ There is lesser representation of female convicts in the study sample.

- Lack of access to detailed previous psychiatric records or collateral informants. A disadvantage of face to face clinical assessment may include recall and self presentation biases, and corroboration of informants with key informants would have strengthened the study.

\section{REFERENCES}

1. Walmsley R. "World Prison Population List (Ninth Edition)"; 2010 [updated 2010 October; cited 2012-12-17].Available from http://www.idcr.org.uk/wp content/2010/09/WPPL-9-22.pdf. [Last accessed on 2013 Feb 12].

2. Gupta RK, Singh GPI, Bhonde AS, Sankhayadar P. Mental Stress amongst Inmates of a Prison. J Ment Health Hum Behav 1998; 3(1):25-8.

3. Goyal SK, Singh P, Gargi PD, Goyal S, Garg A. Psychiatric morbidity in prisoners. Indian J Psychiatry 2011 Jul-Sep; 53(3): 253-7.

4. Chubaty DE .Victimization, fear, and coping in prison. Doctoral Thesis, Winnipeg, MB: University of Manitoba; 2001.

5. Lazarus RS, Folkman S. Stress, appraisal, and coping..New York: Springer Publishing Company; 1984.

6. Zamble E, Porporino FJ. Coping, imprisonment, and rehabilitation: Some data and their implications. Crim Justice Behav 1990; 17(1):53-70.

7. Baum A, Singer JE. Handbook of psychology and health: Stress. Hillsdale,NJ: Erlbaum;1987.

8. Harreveld FV, Claassen L. Inmate emotional coping and psychological and physical well being: the use of crying over spilled milk. Crim Justice Behav 2007; 34(5):697-708.

9. Gautam S, Nijhawan M, Kamal P. Standardization of Hindi version of Goldberg's General Health Questionnaire.Indian J Psychiatry 1987;29:63-6.

10. Jacob KS, Bhugra D, Mann AH. General Health Questionnaire-12: psychometric properties and factor structure among Indian women living in the United Kingdom. Indian J Psychiatry 1997; 39: 196-9. 
11. Sheehan D, LecrubierY, Harnett-Sheehan K, Amorim P, Janavs J, Weiller E. The Mini International Neuropsychiatric Interview (MINI): The development and validation of a structured diagnostic psychiatric interview. J Clin Psychiatry 1998; 59:22-33.

12. Amorim P, Lecurbier Y, Weiller E, Hergueta T, Sheehan D. DSM-III-R Psychotic disorders: procedural validity of the Mini International Neuropsychiatric Interview (MINI).Concordance and causes for discordance with the CIDI. Eur Psychiatry 1998; 13:26-34.

13. Lecrubier Y,Sheehan DV, Weiller E, Amorim P, Bonora I, Sheehan KH. The Mini International Neuropsychiatric Interview (MINI). A short diagnostic structured interview: reliability and validity according to the CIDI. Eur Psychiatry 1997; 12: 224-31.

14. Black DW, Arndt S, Hale N, Rogerson R. Use of Mini International Neuropsychiatric Interview (MINI) as a screening tool in prisons: results of a preliminary study. Jam Acad Psychiatry Law 2004; 32:158-62.

15. Gunter TD, Arndt S, Wenman G, Allen J, Loveless P, Sieleni B. Frequency of mental and addictive disorders among 320 men and women entering the Iowa prison system: use of the MINI-Plus. J Am Acad Psychiatry Law 2008; 36:27-34.

16. Cooper CL, Faragher EB. Coping strategies and breast disorders/ cancer. Psychol Med 1992; 22:447-55.

17. Sharma Y, Mattoo SK, Kulhara P, Sharma SC, Sharan P. Stress and coping in women with cervical and breast cancer in India. Ger J Psychiatry 2003; 6:40-8.

18. Clements CB. 'Crowded Prisons: A Review of Psychological and Environmental Effects'. Law Hum Behav 1979; 3(3): 217-25.

19. Johnson R. Hard time: Understanding and reforming the prison. 2002 3rd ed. Belmont, CA: Wadsworth.

20. Ward D, Kasselbaum G. Women's prison: Sex and social structure. 1965. Chicago: Aldine Publishing Company.

Website(s)

https://en.wikipedia.org/wiki/India 